\title{
Minimal criteria for the diagnosis of megaloblastic anaemia of pregnancy
}

\author{
I. RANNIE AND H. MCTAGGART \\ From the Department of Pathology, King's College, University of Durham, \\ and Royal Victoria Infirmary, Newcastle upon Tyne
}

SYNOPSIS The routine examination of buffy coat films is a valuable diagnostic aid to screening large numbers of specimens of blood and is applicable to hospital and general practice, provided that a bottle of sequestrinated venous blood can be examined in the laboratory within 24 hours.

The diagnosis of folic-acid deficiency anaemia of pregnancy can be made, in many cases, before the appearance of megaloblasts in the peripheral blood by finding macrocytes, polylobing of polymorphonuclear leucocytes, and 'out of step' haemoglobinization of normoblasts in the buffy coat film.

Accurate haemoglobin estimations at intervals throughout pregnancy, and particularly in the last three months, are an important and in some cases essential part of ante-natal care. Any haemoglobin found to be below $75 \%(11.1 \mathrm{~g} . \%)$ should be followed by the examination of a series of buffy coat films while the anaemia is being treated.

It has been shown (Goodall, 1957) that an accurate diagnosis of megaloblastic anaemia of pregnancy can be made by examining films made from the buffy coat layer of centrifuged peripheral blood. Goodall's series was controlled by concurrent sternal marrow examination and he concluded that, although marrow examination was slightly more sensitive than the buffy film, the buffy film alone could supply the necessary information in most cases without subjecting the patient to the discomfort of a marrow puncture.

In this investigation an attempt has been made to discover the minimal information required for a diagnosis of megaloblastic anaemia of pregnancy, and so a record was kept of the haemoglobin, the reticulocyte count, the packed cell volume, and the appearance of the buffy coat film stained by the Leishman method.

The diagnosis of megaloblastic anaemia was not made until megaloblasts appeared in the peripheral blood but we now believe that the diagnosis can in fact be established before this time by taking into account the other haematological appearances and all relevant clinical findings.

Received for publication 10 December 1960.

\section{MATERIALS AND METHODS}

The examinations were carried out on venous blood taken from pregnant women at the ante-natal clinic or in the wards of the Princess Mary Maternity Hospital, Newcastle upon Tyne, over a period of 21 months, from November 1958 to July 1960 inclusive.

All the women in the series were delivered in the hospital although not all of them had received ante-natal care at the hospital clinic.

Specimens were collected in universal containers with Sequestrin (diamino-ethane-tetra-acetic-acid-dipotassium salt) as anticoagulant, and in most cases were not received in the laboratory until the following day, having been stored overnight either at room temperature or $4^{\circ} \mathrm{C}$. and then transported by van.

When the blood specimen was received the haemoglobin was estimated by a cyan-methaemoglobin method using a modified Drabkin's solution (King and Wootton, 1956). If this was $75 \%(11.1 \mathrm{~g} . \%)$ or below, or if the case was already being followed, the reticulocytes and packed cell volume were estimated and a buffy coat film was made.

The packed cell volume was estimated using a Hawksley micro-haematocrit centrifuge, after which the capillary tube containing the blood was cut and the buffy coat and some of the underlying red cells were used to make a smear which was stained with Leishman's stain and examined under a film of oil. We found that a buffy coat 
film made in this way was a good representative sample of all the cells in the peripheral blood.

When examining the film several factors relating to the red cells and white cells were considered and recorded as being present or absent. No attempt was made at a quantitative estimation.

RED CELLS The red cells were examined for anisocytosis, polychromasia, macrocytosis, Howell-Jolly bodies, and nucleated forms. The nucleated forms were further divided into normoblasts, megaloblasts, and cells in which the degree of haemoglobinization was in advance of nuclear maturation. These are referred to as 'out of step' normoblasts. Only nucleated red cells with some degree of haemoglobinization were considered (Goodall, 1957).

WHITE CELLS White cells were examined for the presence of polylobing (hypersegmentation) of the nuclei of neutrophil polymorphonuclear leucocytes or giant forms of metamyelocytes and polymorphonuclear leucocytes. Hypersegmentation was taken to mean six or more clearly defined lobes in the nucleus.

\section{RESULTS}

In the 21 months covered by the survey there were 3,741 births at the maternity hospital, and of that number 45 of the patients were diagnosed as having megaloblastic anaemia during or immediately after their pregnancy. Of the 45 patients, 38 had a single delivery including one who delivered a hydatidiform mole. Five had twin deliveries and two had triplets. Most of the patients were multiparous but nine of them were experiencing their first pregnancy and eight were pregnant for only the second time.

The maternal ages ranged from 21 to 44 years.

It will be seen from Fig. 1 that the haemoglobin level at the time of diagnosis was most commonly between $55 \%$ and $60 \%(8.1$ and $8.9 \mathrm{~g} . \%)$. In only

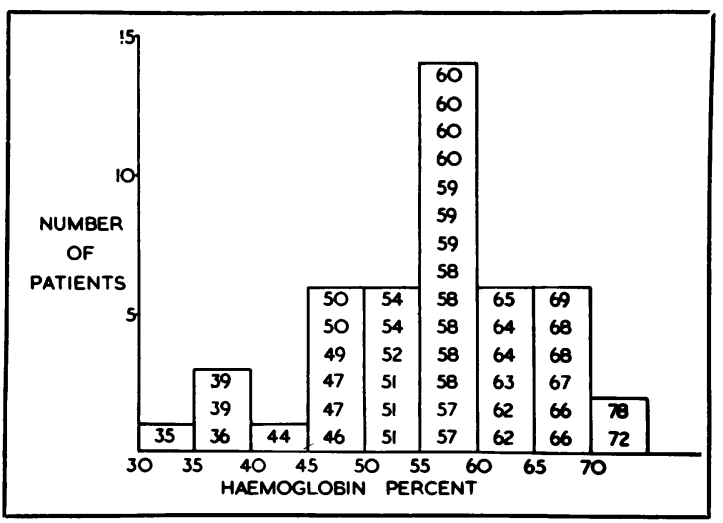

FIG. 1. Histogram showing the haemoglobin level in the individual cases at the time of diagnosis. ( $\mathrm{Hb} \mathrm{100 \% =}$ $14 \cdot 8 \mathrm{~g} .1100 \mathrm{ml}$.) one case was the haemoglobin over $75 \%(11 \cdot 1 \mathrm{~g} . \%)$; this estimation was made after a blood transfusion and gives a wrong impression.

Fig. 2 indicates the time of diagnosis in relation to parturition and it is shown that all the cases except one were diagnosed in the last trimester of pregnancy or the first week of the puerperium. The diagnosis made at 19 weeks was that in the case of molar pregnancy referred to previously. Twenty-two of the cases were diagnosed on the first occasion that a buffy coat film was examined.

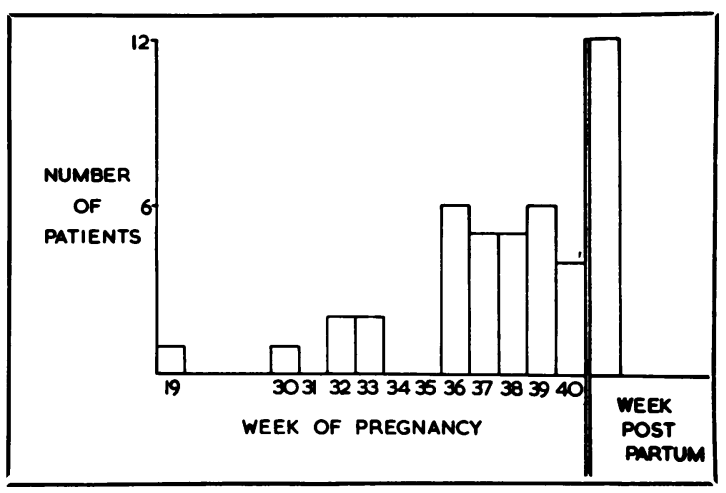

FIG. 2. Diagram illustrating the relationship between megaloblastic anaemia of pregnancy and the week of pregnancy in which it was diagnosed.

\section{ILLUSTRATIVE CASES}

CASE 32 (MRS. M. W.) This patient was 29 years old and in her fourth pregnancy. She was found to have megaloblasts in a buffy film at the thirty-third week of pregnancy on the first occasion that a film was examined (Fig. 3).

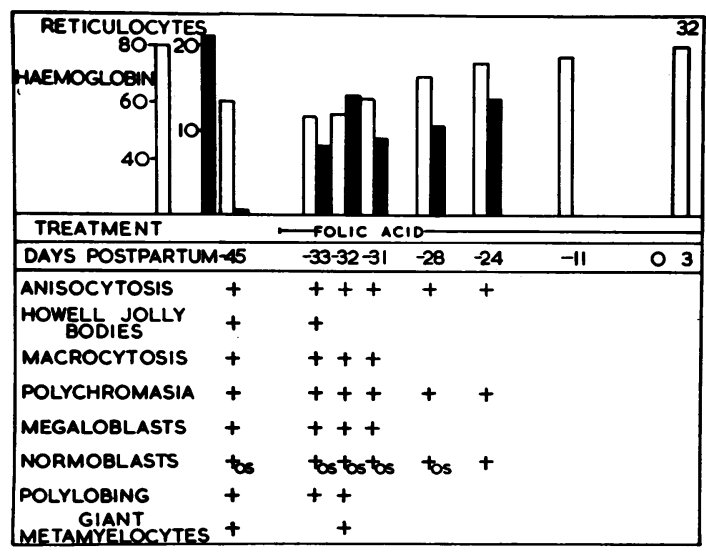

FIG. 3. The time scale is in days post partum so that the minus sign indicates days ante partum. O.S. = Normoblasts with heamogloblinization in advance of nuclear maturation. 
She was treated with folic acid orally and by the time she reached her thirty-ninth week, the haemoglobin was $76 \%(11.3$ g. $\%)$. Shortly after delivery it was $80 \%$ $(11.8 \mathrm{~g} . \%)$. No blood transfusion was required and there was no complication.

CASE 4 (MRS. E. A.) This patient, like the last, was 29 years old and in her fourth pregnancy. During the series it was found in several cases that the megaloblastic picture appeared after a course of intramuscular or intravenous iron injections. In this case (Fig. 4) a course of Imferon injections was followed by the appearance of megaloblasts in a specimen taken before delivery on the day of delivery. In spite of the Imferon the haemoglobin level had dropped slightly and the reticulocyte count remained at $1 \%$. The anaemia was later treated with oral iron and folic acid.

CASE 39 (MRS. D. M.) This patient was 27 years old and was in her fourth pregnancy. On the first occasion that a buffy film was examined, more than six weeks before delivery, her blood picture was one which we came to recognize later as typical of folic-acid deficiency anaemia (Fig. 5). No megaloblasts were seen but the film showed macrocytes, polylobing of polymorphonuclear leucocytes, and 'out of step' haemoglobinization of normoblasts. During a course of Ferrivenin megaloblasts appeared, but only four days before the delivery and when the haemoglobin was $60 \%(8.9 \mathrm{gg} \%)$.

CASE 34 (MRS. C. W.) This patient is included as representative of the group of nine primiparae. She was 23 years old and was diagnosed in the first week post partum after having had a transfusion of 2 pints of blood at delivery. However, it is again seen that macrocytes, polylobing, and 'out of step' haemoglobinization were present in the peripheral blood a month earlier (Fig. 6) so that a diagnosis could have been made at the time.

There was one maternal death in our series of 45 patients. A woman of 21 , who was pregnant for the first time, was admitted as an emergency with a fulminating pre-eclamptic toxaemia and died 12 days after delivery in renal failure, with a haemoglobin level of $35 \%(5 \cdot 2 \mathrm{~g} . \%)$. At necropsy it was considered that megaloblastic anaemia had played a part in the death.

\section{DISCUSSION}

While examining buffy films it became clear that folicacid deficiency anaemia of pregnancy could be diagnosed, in many cases, before the appearance of megaloblasts in the peripheral blood. The presence of macrocytosis, polylobing of neutrophil polymorphonuclear leucocytes, and 'out of step' haemoglobinization of normoblasts was followed, in the absence of treatment with folic acid, by the full megaloblastic picture.

The advantage of using the other criteria when

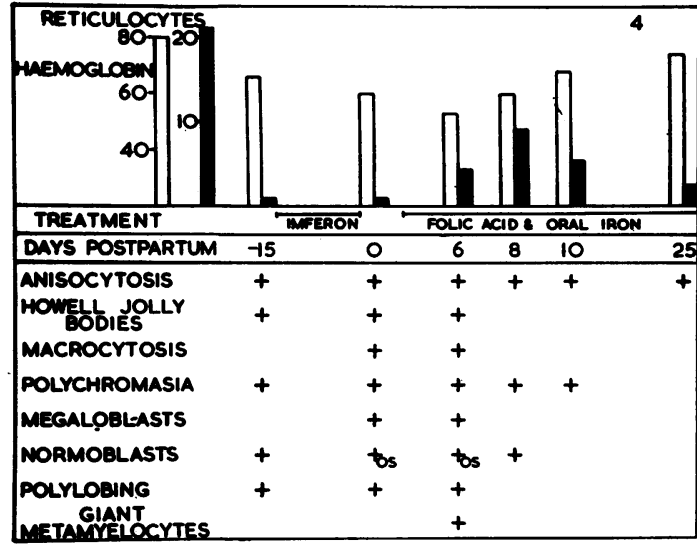

FIG. 4

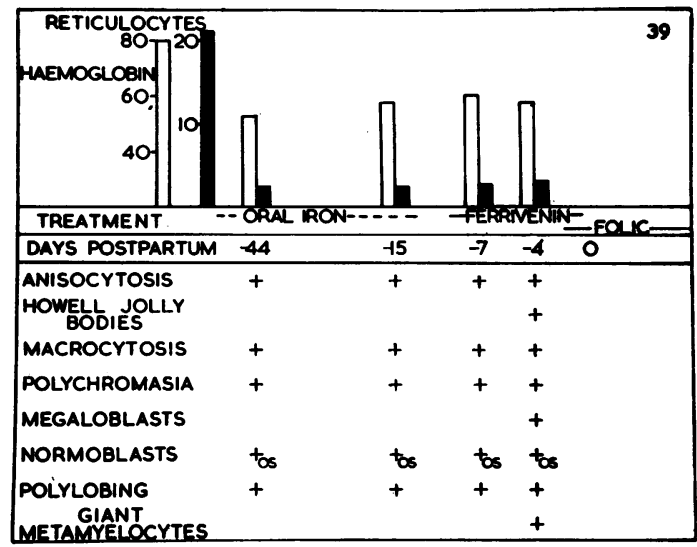

FIG. 5

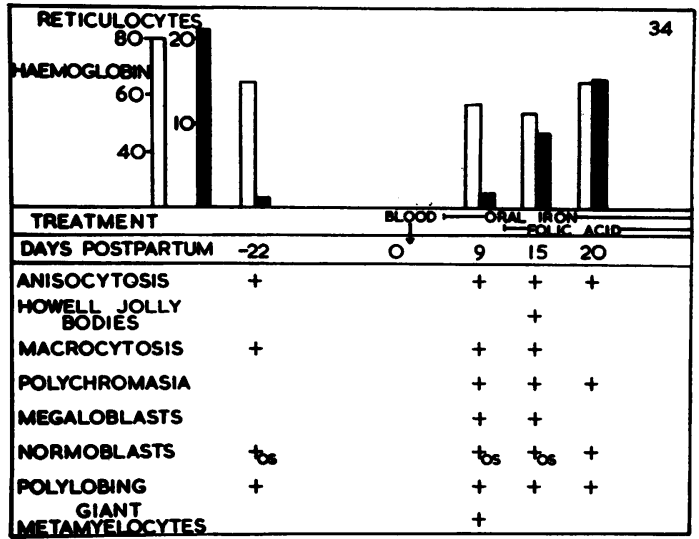

FIG. 6

FIGS. 4, 5, AND 6. The time scale is in days post partum so that the minus sign indicates days ante partum. O.S. = Normoblasts with haemoglobinization in advance of nuclear maturation. 
present is that treatment can be started earlier than would otherwise be the case (Cases 34, 39).

The danger of masking a true Addisonian pernicious anaemia in pregnancy and consequently precipitating subacute combined degeneration of the cord by giving folic acid would be largely overcome by further investigations of any suspected case and medical supervision during folic-acid therapy. While not altogether condemning the use of folic acid as a routine prophylactic in pregnancy we feel that it is an unnecessary and costly refinement. Even if it were used in this way the need for a simple screening method would still exist because of such factors as poor absorption of folic acid from the bowel or neglect by the patient, resulting in too small a dose or perhaps none at all.

We should like to thank the consultant staff of the Princess Mary Maternity Hospital, Newcastle upon Tyne, for access to case notes.

\section{REFERENCES}

Goodall, H. B. (1957). J. clin. Path., 10, 248.

King, E. J., and Wootton, I. D. P. (1956). Micro-analysis in Medical Biochemistry, 3rd ed.. p. 37. Churchill, London.

\section{The July 1961 Issue}

\section{THE JULY 1961 ISSUE CONTAINS THE FOLLOWING PAPERS}

Studies on the folic acid activity of human serum A. H. WATERS and D. L. MOLLIN

Conventional voltage electrophoresis for formiminoglutamic acid determination in folic acid deficiency J. KOHN, D. L. MOLLIN, and L. M. ROSENBACH

The urinary excretion of assavable vitamin $B_{12}$ and radioactivity after parenteral ${ }^{58} \mathrm{Co} B_{12}$ in man $J$. $F$. ADAMS

A suggested schedule for the rapid investigation of acute haemostatic failure G. I. C. INGRAM

Studies on the blood lipids and lipoproteins in thalassaemia and sickle cell anaemia c. CHOREMIS, v. KYRIAKIDÈs, and E. PAPADAKIS

Hereditary elliptocytosis in two Maltese familes. J. L. GRECH, E. A. CACHIA, F. CALleja, and F. PULlicino

The significance of Howell-Jolly bodies and giant metamyelocytes in marrow smears D. W. DAWSON and $\mathrm{H}$. P. R. BURY

The rate of blood loss from skin punctures during the Ivy bleeding time test M. L. N. WILLOUGHBY and M. J. ALLINGTON

Methicillin-resistant staphylococci MARY BARBER

Coccidiosis in guinea-pigs P. A. ElLIS and A. E. WRIGHT

Rapid isolation of salmonellae from faeces J. M. S. DIXON

The estimation of magnesium in small biological samples by flame spectrophotometry R. D. MONTGOMERY

The determination of magnesium in biological materials by flame photometry J. K. FAWCETT and V. WYNN
Plasma magnesium in health and disease SAMIR HANNA A possible source of error in the diagnosis of phaeochromocytoma D. W. NEILL, I. J. CARRÉ, R. L. MCCORRY, and R. H. THOMPSON

A sensitive method for the colorimetric determination of urea R. N. BEALE and D. CROFT

The use of tetramethylammonium hydroxide in the Zimmermann reaction v. H. T. JAMES and MARY DE JONG

Laboratory studies with the systemic trichomonacide, metronidazole R. F. JENNISON, P. STENTON, and LESLIE WATT

Paper tests for occult blood in faeces and some observations on the fate of swallowed red cells R. G. HUNTSMAN and J. LIDDELL

\section{Technical methods}

Quantitative determination of A2 haemoglobin by paper electrophoresis using tris buffer R. T. S. JIM

A method of rapid $\mathrm{Rh}$ typing employing the capillary tube technique and papainized incomplete anti-D sera B. E. GILBEY

The rapid slide agglutination test in the diagnosis of typhoid fevers and typnus B. $z$. WERBIN and A. KASHER

Haemoglobinometry by an automatic analytical procedure M. G. NELSON and A. LAMONT

Improvement of the uric acid determination by the carbonate method for serum and urine F. EICHHORN, S. ZELMANOWSKI, E. LEW, A. RUTENBERG, and B. FANIAS

Book reviews

Copies are still available and may be obtained from the PUBLISHING MANAGER, BRITISH MEDICAL ASSOCIATION, TAVISTOCK SQUARE, W.C.I, price 17s. 6D. 